\title{
Heterogeneity of Campylobacter species isolated from serial stool specimens of Egyptian children using pulsed field gel electrophoresis
}

\begin{tabular}{|c|c|}
\hline $\begin{array}{l}\text { Authors: } \\
\text { Atef M. El-Ge } \\
\text { Momtaz O. W } \\
\text { Adel M. Mans } \\
\text { Buhari Oyofo } \\
\text { Marwa M. Yo } \\
\text { John D. Klena }\end{array}$ & $\begin{array}{l}\text { dy }{ }^{1} \\
\text { asfy } \\
\text { our } \\
\end{array}$ \\
\hline $\begin{array}{l}\text { Affiliations: } \\
{ }^{1} \text { United State } \\
\text { Medical Rese }\end{array}$ & $\begin{array}{l}\text { Naval } \\
\text { arch, Egypt }\end{array}$ \\
\hline \multicolumn{2}{|c|}{$\begin{array}{l}{ }^{2} \text { Central Public Health } \\
\text { Laboratories, Egypt }\end{array}$} \\
\hline \multicolumn{2}{|c|}{$\begin{array}{l}{ }^{3} \text { United States Centers } \\
\text { for Disease Control and } \\
\text { Prevention, China }\end{array}$} \\
\hline \multicolumn{2}{|c|}{$\begin{array}{l}\text { Correspondence to: } \\
\text { Atef El Gendy }\end{array}$} \\
\hline \multicolumn{2}{|c|}{$\begin{array}{l}\text { Email: } \\
\text { atef.elgendy.eg@med.navy. } \\
\text { mil }\end{array}$} \\
\hline \multicolumn{2}{|c|}{$\begin{array}{l}\text { Postal Address: } \\
\text { United States Naval Medical } \\
\text { Research Unit No.3, } \\
\text { PSC } 452 \text { Box 5000, FPO, AE, } \\
\text { 09835-0007, USA }\end{array}$} \\
\hline $\begin{array}{l}\text { Dates: } \\
\text { Received: } 02 \\
\text { Accepted: } 25 \\
\text { Published: } 26\end{array}$ & $\begin{array}{l}\text { Apr. } 2012 \\
\text { Oct. } 2012 \\
\text { July } 2013\end{array}$ \\
\hline \multicolumn{2}{|c|}{$\begin{array}{l}\text { How to cite this article: } \\
\text { El-Gendy AM, Wasfy MO, } \\
\text { Mansour AM, Oyofo B, Yousry } \\
\text { MM, Klena JD. Heterogeneity } \\
\text { of Campylobacter species } \\
\text { isolated from serial stool } \\
\text { specimens of Egyptian } \\
\text { children using pulsed field } \\
\text { gel electrophoresis. Afr J } \\
\text { Lab Med. 2013;2(1), Art. } \\
\text { \#34, } 9 \text { pages. http://dx.doi. } \\
\text { org/10.4102/ajlm.v2i1.34 }\end{array}$} \\
\hline \multicolumn{2}{|c|}{$\begin{array}{l}\text { OpenJournals. This w } \\
\text { is licensed under the } \\
\text { Creative Commons } \\
\text { Attribution License. }\end{array}$} \\
\hline \multicolumn{2}{|l|}{ Read online: } \\
\hline 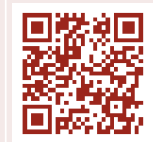 & $\begin{array}{l}\text { Scan this QR } \\
\text { code with your } \\
\text { smart phone or } \\
\text { mobile device } \\
\text { to read online. }\end{array}$ \\
\hline
\end{tabular}

Authors:

\section{Affiliations:}

${ }^{1}$ United States Nava

${ }^{2}$ Central Public Health

Laboratories, Egypt

${ }^{3}$ United States Centers for Disease Control and

Prevention, China

Atef El Gendy

\section{Email:}

atef.elgendy.eg@med.navy.

\section{Postal Address:}

United States Naval Medical Research Unit No.3, PSC 452 Box 5000, FPO, AE, 09835-0007, USA

Accepted: 25 Oct. 2012

Published: 26 July 2013

How to cite this article: El-Gendy AM, Wasfy MO, Mansour AM, Oyofo B, Yousry of Campylobacter species isolated from serial stool specimens of Egyptian children using pulsed field gel electrophoresis. Afr J Lab Med. 2013;2(1), Art. \#34, 9 pages. http://dx.doi. org/10.4102/ajlm.v2i1.34

\section{Licensee: AOSIS \\ OpenJournals. This work}

Background: The genus Campylobacter spp. is a common cause of human acute bacterial enteritis and travellers' diarrhoea worldwide.

Objective: To determine whether multiple serial isolations of Campylobacter spp., when obtained from a single child, represented the same or a different organism.

Methods: In a birth cohort study conducted in Egypt, numerous children showed serial isolations of Campylobacter spp. Of these, 13 children were selected from different households based on the successive isolation of six or more Campylobacter isolates from stool samples.

Results: Eighty isolates were recovered and identified as either Campylobacter coli $(n=25)$ or Campylobacter jejuni $(n=55)$. Pulsed-field gel electrophoresis (PFGE) revealed the presence of 38 unique $C$. jejuni and 24 C. coli profiles at a similarity level of $\geq 90 \%$. Although no seriallyidentical isolates were detected in six children, others demonstrated at least one identical couple of isolates; all identified serially between one to six weeks. Two children demonstrated $>80 \%$ similar couples of isolates that appeared seven months apart. PFGE could be a useful tool for differentiating reinfection, relapse and convalescent excretion phases.

Conclusion: Our data suggest that Campylobacter infection in children is a complex process; children are exposed to multiple species in endemic environments and strains of the same bacterium appear to be shed serially between one to six weeks after the first exposure. Isolates that persisted for longer periods were relatively less similar, as shown from the results of this study.

\section{Introduction}

The genus Campylobacter comprises a group of closely-related gram-negative bacteria which primarily colonise the gastrointestinal tracts of a wide variety of host species. ${ }^{1}$ Campylobacter jejuni and Campylobacter coli are common causes of human acute bacterial enteritis worldwide. ${ }^{2}$ In Egypt, the disease causes severe problems, with both acute and chronic clinical manifestations in infants aged less than two years, and is a known cause of travellers' diarrhoea. ${ }^{3,4}$ Investigations have been complicated by the growth requirements of the bacteria, differences in pathogenic mechanisms and the possibility for molecular variability, constituting a substantial challenge for many scientific disciplines. ${ }^{5}$ Pulsed-field gel electrophoresis (PFGE) has been used for the molecular subtyping of Campylobacter species and is capable of intraspecies differentiation. ${ }^{6}$ In developed countries, most Campylobacter infections result from a unique exposure; reports of repeated infections are uncommon. The purpose of this study was to assess whether multiple serial isolations of Campylobacter spp., when obtained from a single child, represented the same or a different organism. We used PFGE analysis on a unique set of Campylobacter spp. isolates collected during a birth cohort study performed in the Nile Delta region of Egypt to answer this question. Participating children had diarrhoeal and non-diarrhoeal stool samples collected over a two-year period and the microbiological content of these samples was investigated. We selected a set of children who had a minimum of six successive Campylobacter spp. isolations during this time, and we examined these isolates by PFGE to determine if the isolates were the same species and the same pulsetype, based on SmaI restriction enzyme digestion. ${ }^{7}$

\section{Research method and design Campylobacter isolates}

Isolates used in this study were collected from children participating in a birth cohort study conducted in a rural district of the Nile Delta, Egypt, between January 2004 and April 2007. Overall, 13 children showing six or more Campylobacter isolates with at least one diarrhoeal 
episode over a period of two years were chosen randomly for this study. The children resided in five different villages and had a median age of eight months (range 3-14 months) at first isolation of Campylobacter spp., and none were bottlefed. Stool samples were generally collected every other week if no diarrhoea was reported. When diarrhoea was reported, two rectal swabs and a stool specimen were obtained.

Campylobacter colonies were recovered from Skirrow's medium and confirmed by colonial morphology and gram stain, as well as oxidase and catalase activity. ${ }^{8,9}$ Speciation was performed using hippurate hydrolysis (positive for C. jejuni and negative for C. coli isolates $)^{8,10}$ and multiplex polymerase chain reaction $(\mathrm{MPCR})$ based on the nucleotide sequence of the lipid A gene, $l p x A \cdot{ }^{11}$

\section{Antibiotic susceptibility}

Antibiotic susceptibility measurements were made using the Epsilometer test (Etest) (AB Biodisk, Solna, Sweden) according to the manufacturer's instructions. Etests were used to determine the minimum inhibition concentrations (MIC) of isolates against ciprofloxacin and erythromycin. Suspensions of the organisms were prepared in $5 \mathrm{ml}$ of Mueller-Hinton broth and adjusted to a turbidity of $1 \mathrm{McF}$ arland standard. ${ }^{12,13}$ The antibiotic susceptibility tests were performed from the adjusted inocula. ${ }^{9}$ Standardised bacterial suspensions were used to inoculate Mueller-Hinton agar supplemented with 5\% defibrinated sheep blood. Excess moisture was allowed to be absorbed for about 10 to 15 minutes. When the surface of each plate had dried, Etest strips were placed aseptically on the plates (using sterile forceps). The plates were incubated within 15 minutes of applying the Etest strips in microaerophilic conditions $\left(5 \% \mathrm{O}_{2}, 7.5 \% \mathrm{CO}_{2}, 7.5 \% \mathrm{H}_{2}, 80 \%\right.$ $\mathrm{N}_{2}$ ) by using CampyPak Microaerophilic System Envelopes (Becton, Dickinson and Company, Loveton Circle Sparks, MD, USA) at $37{ }^{\circ} \mathrm{C}$ for 48 hours. MICs were read directly from the Etest strip at the point where the elliptical zone of inhibition intersects the MIC scale on the strip. Quality control strains (C. jejuni ATCC 33291 and C. coli ATCC 33559) were tested exactly the same as the clinical isolates ${ }^{14}$. MICs and disk-diffusion breakpoints for antibiotic resistance and susceptibility of Campylobacter isolates were determined according to Table 1 as described previously. ${ }^{14}$

\section{Pulsed-field gel electrophoresis}

Intact deoxyribonucleic acid (DNA) was prepared from isolates from each child and digested as described previously ${ }^{7}$ using the U.S. Centers for Disease Control and Prevention (CDC) Pulsenet protocol for foodborne disease surveillance ${ }^{7}$ using a CHEF Mapper (Bio-Rad, CA, USA). Agarose gels were stained with ethidium bromide $(50 \mu \mathrm{g} / \mathrm{ml})$ and DNA band patterns were viewed by ultraviolet (UV) illumination. Gel images were captured and analysed using the BioNumerics Software package (version 5.10; Applied Maths, Austin, TX, USA). Similarity between pulsetypes was calculated using the Dice coefficient with a $2 \%$ tolerance for the band migration distance and clustering was performed using the complete linkage method (furthest neighbour) that considers the distance between any two given clusters as being the maximum distance between these clusters to reveal straggly clusters or outliers. This analysis method is considered to be a more strict interpretation of banding patterns than the unweighted pair group method using arithmetic averages (UPGMA). ${ }^{7}$

\section{Results}

We examined 87 Campylobacter single-colony isolates collected from 13 children; 12 children showing six separate Campylobacter isolations, whilst 15 Campylobacter isolates were recovered from the remaining child over a period of 13 months. Of these isolates, seven were mixed C. jejuni and C. coli and were eliminated from further analysis.

Amongst the 13 children, nine demonstrated diarrhoea due to $C$. jejuni (Child 1, 2, 3, 4, 5, 7, 8, 9, 13), three due to C. coli only (Child $6,10,12)$, and one child had episodes resulting from infection with both Campylobacter species (Child 11) (Figures 1-5). The number of diarrhoeal episodes varied amongst the children, with six showing a single episode (Child 1, 2, 5, 6, 8, 12) and three showing two episodes (Child $4,7,10)$, whilst two had three episodes (Child 9, 13) or even four (Child 3, 11).

Although no serially-identical isolates were detected in six children (Child 1, 2, 4, 6, 8, 10), others demonstrated at least one identical couple of isolates (Child 3, 5, 7, 9, 11, 12, 13), all identified at one to six week intervals from each other. Two children demonstrated $\geq 80 \%$ similar couples of isolates (Child 6,8) that appeared seven months and one year apart, respectively. Child 7, 9, 11 and 12 had only five unique isolates, since each had one identical serial isolate that was recovered after one to six weeks. Only three children had more than one pair of indistinguishable Campylobacter isolates associated with their stools (Child 3, 5, 13). Confirmation of Campylobacter spp. isolates was conducted with the $\operatorname{lp} x \mathrm{~A}$ mPCR; 55 C. jejuni and 25 C. coli species were identified. Comparing phenotypic and genetic methods, seven $C$. jejuni isolates (8\%) failed to hydrolyse hippurate and would have been misclassified using phenotypic methods alone. Most diarrhoeal episodes were due to C. jejuni (19/24, 79\%); all six Campylobacter isolates recovered from two children

TABLE 1: Breakpoints for antibiotic susceptibility and resistance.

\begin{tabular}{llcc}
\hline Antibiotic & $\begin{array}{l}\text { Disk diffusion } \\
\text { Breakpoints for susceptibility }\end{array}$ & \multicolumn{1}{c}{ S } & MICs \\
\cline { 2 - 4 } Erythromycin & $\geq 20 \mathrm{~mm}$ & MICs of 0.06 to $4 \mu \mathrm{g} / \mathrm{ml}$ & I \\
Ciprofloxacin & $\geq 21 \mathrm{~mm}$ & MICs of 0.06 to $0.25 \mu \mathrm{g} / \mathrm{ml}$ & MICs of $2 \mu \mathrm{g} / \mathrm{ml}$ \\
\hline
\end{tabular}

Abbreviations: R: Resistant, S: susceptible, I: intermediate. 


\section{C. jejuni Smal profiling (55 entries)}

Dice (Tol 1.5\%-1.5\%) (H>0.0\% S > 0.0\%) [0.0\%-100.0\%] Ca-reinfect

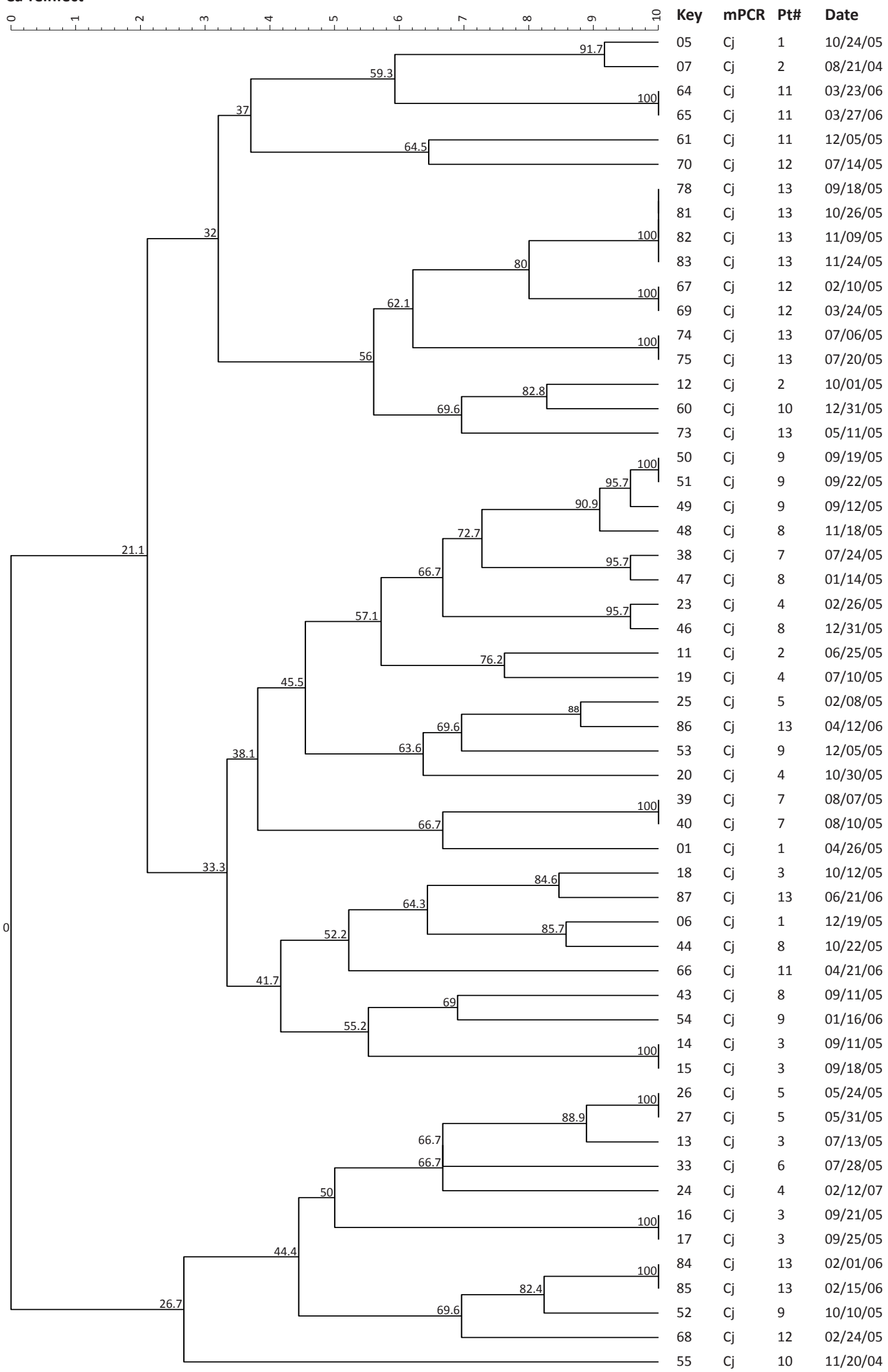

FIGURE 1: Smal macrorestriction profiling of $C$. jejuni isolates by pulsed-field gel electrophoresis.

Key, strain number; mPCR, multiplex PCR; Pt\#, child number; Date, date of isolation at the US Naval Medical Research Unit No. 3, laboratory; CJ, C. jejuni Resistant. 
(Child 3,9) were C. jejuni and at least one C. jejuni isolate was recovered from the remaining 11 children, who also had at least one $C$. coli isolate recovered, although no child was exclusively positive for only C. coli.

Excluding the seven mixed infections, $86 \%(69 / 80)$ of the Campylobacter isolates were resistant to ciprofloxacin (CIP), an antibiotic often selected for treatment of campylobacteriosis. ${ }^{15}$ Only $5 \%(n=3 / 55)$ of the C. jejuni isolates were susceptible to ciprofloxacin; however $32 \%(n=8 / 25)$ of $C$. coli were susceptible. All isolates were susceptible to erythromycin. Table 2 shows the results of the susceptibility testing.

Because stool samples were collected from children routinely over a two-year period, we were able to look at whether a single Campylobacter isolate persisted in a child, or if that child was colonised (infected) by multiple isolates.

We utilised the discriminatory power of PFGE to assess the relationship of isolates recovered from each child (Figures 1-5), as well as to provide an overall picture of the Campylobacter population associated with the children (Figures 1 and 2). We

TABLE 2: Susceptibility testing of Campylobacter isolates.

\begin{tabular}{lccccc}
\hline Reaction & \multicolumn{2}{c}{ Disk Diffusion Test } & & \multicolumn{2}{c}{ MIC by Etest } \\
\cline { 2 - 3 } \cline { 5 - 6 } & Erythromycin & Ciprofloxacin & & Erythromycin & Ciprofloxacin \\
\hline Resistant & 0 & $75(86 \%)$ & & 0 & $75(86 \%)$ \\
Susceptible & $87(100 \%)$ & $12(14 \%)$ & & $87(100 \%)$ & $12(14 \%)$ \\
\hline
\end{tabular}

\section{C.coli - Smal profiling (25 entries)}

Dice (Tol 1.5\%-1.5\%) (H>0.0\% S > 0.0\%) [0.0\%-100.0\%] Ca-reinfect



FIGURE 2: Smal macrorestriction profiling of $C$. coli isolates by pulsed-field gel electrophoresis.

Key, strain number; mPCR, multiplex PCR; Pt\#, child number; Date, date of isolation at the US Naval Medical Research Unit No. 3, laboratory; CJ, C. jejuni Resistant. grouped the children into four categories, namely, (1) children exposed to multiple species and strains of Campylobacter spp., (2) pre-diarrhoeal to diarrhoeal, (3) diarrhoeal-shedding and (4) active infection only.

\section{Exposure determined by pulsed-field gel electrophoresis analysis}

Using PFGE at $\geq 90 \%$ similarity level, it was found that six children had six unique (dissimilar) Campylobacter isolates, (for example, the six isolates recovered from Child 1) (Isolates 1-6; Figure 3) were unique. The first isolate was recovered when Child 1 was eight months old and the last at 16 months. Child 1 was colonised by both $C$. jejuni $(n=3)$ and C. coli $(n=3)$ during this eight-month period and all of the isolates had distinguishable SmaI PFGE profiles. Only Isolate 6 (C. jejuni) was associated with diarrhoea. The same pattern was observed in Child 2, 4 and 8. Child 6 and 10 showed the same pattern, but demonstrated diarrhoea due to C. coli. The data suggest that children are exposed to a wide range of strains of C. coli and C. jejuni.

In Child 2, diarrhoea was associated with only one C. jejuni isolate (Isolate 12) that was CIP-resistant and 64\% similar to a forerunner (Isolate 11), but appeared three months earlier. All C. coli isolates were recovered from that child without symptoms at one to three month intervals and exhibited $28 \%-64 \%$ similarity. In Child 6 (Figure 3), diarrhoea was associated with a single C. coli isolate (Isolate 32 ) that was $83.3 \%$ similar to another (Isolate 31 ) that had been identified four days earlier and was $21.1 \%$ similar to a third (Isolate 33) recovered 10 days later. Child 8 (Figure 4) demonstrated one diarrhoeal episode due to C. jejuni (Isolate 44), whilst disease in Child 10 was associated with one C. coli isolate (Isolate 58) that was $32 \%$ similar to another C. coli successor (Isolate 59) isolated 28 days later.

\section{Recovery of pre-diarrhoeal to diarrhoeal isolates}

Of the six isolates recovered from Child 7 (Figure 4), two (Isolate 38, 40) were associated with diarrhoea. Both isolates were $C$. jejuni and were recovered just over two weeks apart (24 July 2005 and 10 August 2005); however, these isolates were readily distinguishable by PFGE analysis (Figure 4). A third C. jejuni isolate (Isolate 39), recovered on 7 August 2005 from a routine (non-diarrhoeal) sample, was indistinguishable from Isolate 40 . The scenario suggested by the PFGE patterns is that after infection by Isolate 38, Child 7 was re-colonised by a new strain of Campylobacter (Isolate 39) that was also able to cause an infection that resulted in diarrhoea (recovery of Isolate 40). Prior to and after these $C$. jejuni infections, $C$. coli was recovered from Child 7 (Isolate 37, 10 July 2005 and Isolate 41, 4 September 2005, respectively). Interestingly, the final isolate from Child 7 was a mixed infection (Isolate 42, 18 September 2005). It is unclear from the PFGE profile whether this mixed infection was two previously-documented isolates, new isolates, or a combination of old and new isolates. PFGE results from Child 7 (Figure 4) indicate a complicated microbiological milieu, since six Campylobacter isolates were 
recovered from this child over a three-month span. The first, Isolate 37 (C. coli), was not associated with diarrhoea, but Isolate 38 (C. jejuni), recovered 14 days later, was.

\section{Recovery of diarrhoea to shedding isolates}

For Child 5, three C. jejuni and three C. coli isolates were recovered over a 12-month period (Figure 3). After initial recovery of a $C$. jejuni isolate (Isolate 25) that was not associated with diarrhoea, a second distinguishable $C$. jejuni isolate (Isolate 26), associated with diarrhoea, was recovered three months later. Isolate 26 had an indistinguishable pulsetype from Isolate 27, a non-diarrhoea-associated C. jejuni recovered one week later. One distinguishable $C$. jejuni and three distinct $C$. coli isolates were recovered prior to and after the Campylobacter-associated diarrhoea caused by Isolate 26 . In addition, the recovery of indistinguishable Isolates 29 and 30 two weeks apart (Figure 3) highlights the possibility of carriage of Campylobacter spp. for extended periods of time, although not necessarily associated with diarrhoea.

A similar story is presented by Child 13, from whom 15 Campylobacter isolates were recovered. This child demonstrated 11 serial isolates of $C$. jejuni (Figure 5). Of these, two identical strains (Isolate 74, 75) were recovered at an interval of two weeks, but did not cause diarrhoea. Two months later, two diarrhoeal episodes occurred as a result of infection by an identical couple of isolates (Isolate 78,81 ) that persisted for four weeks without diarrhoea (Isolate 82, 83). Three months later, two identical strains (Isolate 84, 85) persisted for two weeks with $41.4 \%$ similarity to the preceding two clusters (Isolate 74, 75, 78, 81, 82, 83).

Child 13 continued to shed Isolate 81 for nearly a month (along with recovery of indistinguishable Isolates 82 and 83 up until 24 November 2005), after which time we no longer recovered this pulsetype.

The data from these two children suggest that $C$. jejuni can be shed for at least one week and for as long as six weeks after active infection. In a Campylobacter-endemic environment, it also appears that multiple colonisation events, involving different species and strains, can take place during this time.

Child 12 continued to shed C. jejuni Isolate 67 for nearly six weeks (recovery of indistinguishable isolates 67 and 69, 24 March 2005); however, this child only demonstrated diarrhoea resulting from C. coli infection (Isolate 71), recovered 9 months later.

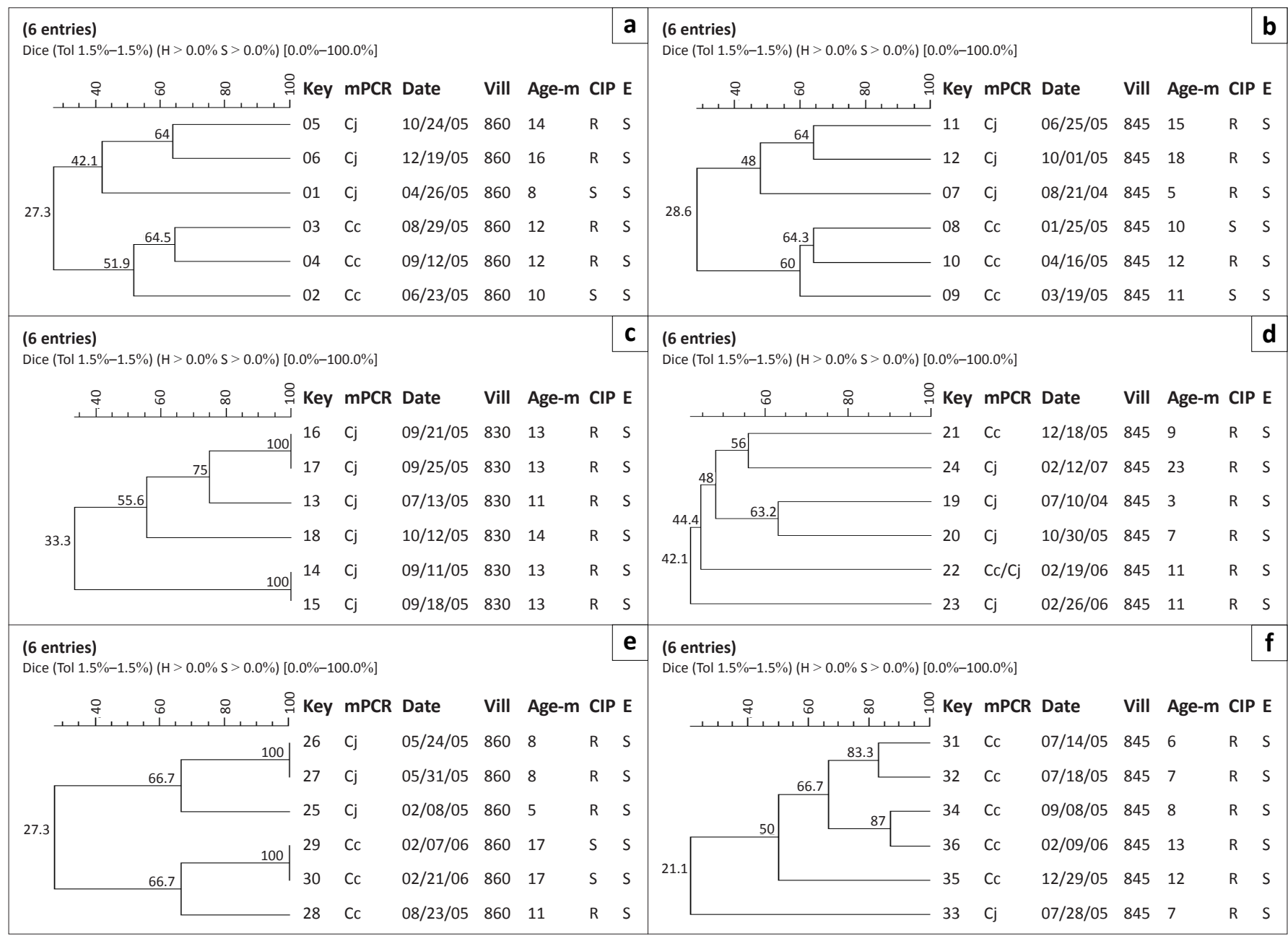

FIGURE 3: Smal macrorestriction profiling of Campylobacter spp. isolates from (a) child 1, (b) child 2, (c) child 3, (d) child 4, (e) child 5, (f) child 6.

Abbreviations: Key: strain \#; mPCR: Date: date of isolation at the US Naval Medical Research Unit No. 3, laboratory; multiplex PCR, Pt\#: child \#, Vill: Village \#, Age-m: Age in months, Cc: C. coli, CJ: C. jejuni, R: resistant, S: susceptible, CIP: ciprofloxacin, E: erythromycin. 


\section{Only active diarrhoea observed}

Child 3 (Figure 3 ) had five C. jejuni isolates associated with diarrhoea (Isolate 14, 15, 16, 17, 18), with two pairs (Isolates 14 and 15, 16 and 17) being indistinguishable from each other by PFGE analysis. In each case, the respective pairs were recovered less than a week apart (11 September 2005 and 18 September 2005; 21 September 2005 and 25 September 2005). C. jejuni was also recovered prior to the first diarrhoeal episode (Isolate 13, 13 July 2005), but this isolate was distinguishable from all of the other recovered isolates from Child 3. Additionally, Isolate 18, recovered after Isolate 17 (12 October 2005), was also associated with diarrhoea. Isolate 18 was also distinct from all other Child 3 isolates.

Likewise, the remaining two children (Child 9, 11) had multiple isolates associated with diarrhoea and whilst we were able to recover Campylobacter spp. after these diarrhoeal episodes, we could not recover an isolate with a pulsetype that was distinguishable from the diarrhoeal cause.

In Child 11, a single diarrhoeal episode resulted in the recovery of two indistinguishable $C$. jejuni isolates (Isolate 64, 65; Figure 4). However, these isolates were distinct from two Campylobacter-associated diarrhoea isolates (Isolate 62,
63), both of which were C. coli. PFGE analysis also suggests that Isolates 62 and 63 were distinct; indicating that Child 11 had three consecutive Campylobacter-associated diarrhoeas involving two species and three unique isolates. Whilst a final C. jejuni was recovered from Child 11 after the diarrhoea caused by Isolates 64 and 65 , this isolate had a unique PFGE pattern. Child 9 was unique in that only C. jejuni $(n=6)$ was recovered from this child who showed three successive episodes (Isolates 50-52; CIP-resistant).

\section{Ethical considerations}

This study was supported by the U.S. Department of Defense (DoD) Global Emerging Infections System (GEIS), DoD 31934 NAMRU3. 2003. Ethical considerations and informed consent forms were reviewed and approved by both the Institutional Review Board (IRB) of the US Naval Medical Research Unit No. 3 and the Egyptian Ministry of Health in compliance with all Federal regulations governing the protection of human subjects (IRB Protocol No.145, step D, titled: 'Natural Immunity to ETEC Infections in Egyptian Infants and Children'.

Voluntary participation was adopted, with freedom to withdraw. No major lapses were observed. Informed consent

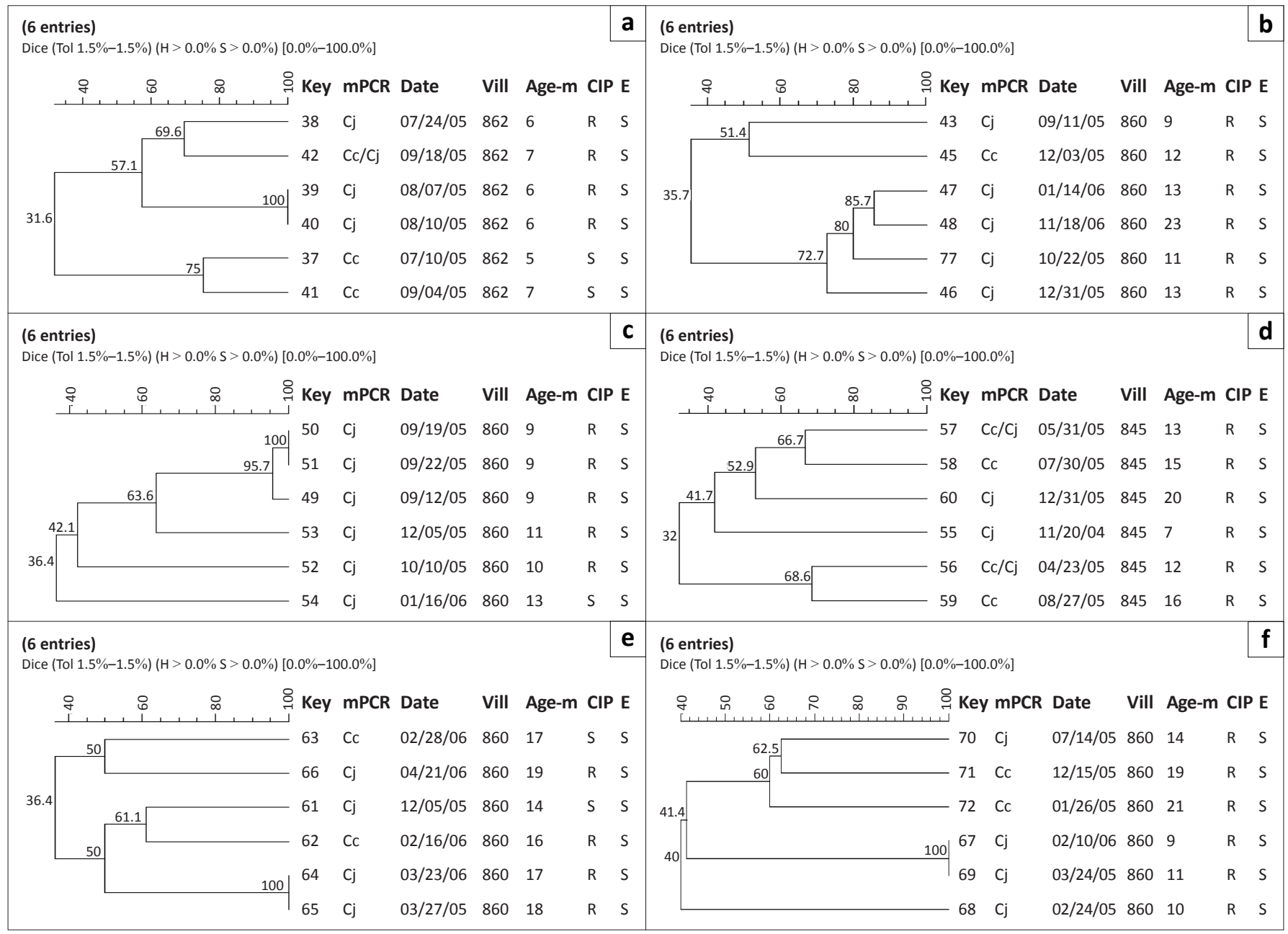

FIGURE 4: Smal macrorestriction profiling of Campylobacter spp. isolates from (a) child 7, (b) child 8, (c) child 9, (d) child 10, (e) child 11, (f) child 12.

Abbreviations: Key: strain \#; mPCR: Date: date of isolation at the US Naval Medical Research Unit No. 3, laboratory; multiplex PCR, Pt\#: child \#, Vill: Village \#, Age-m: Age in months, Cc: C. coli, CJ: C. jejuni, R: resistant, S: susceptible, CIP: ciprofloxacin, E: erythromycin. 


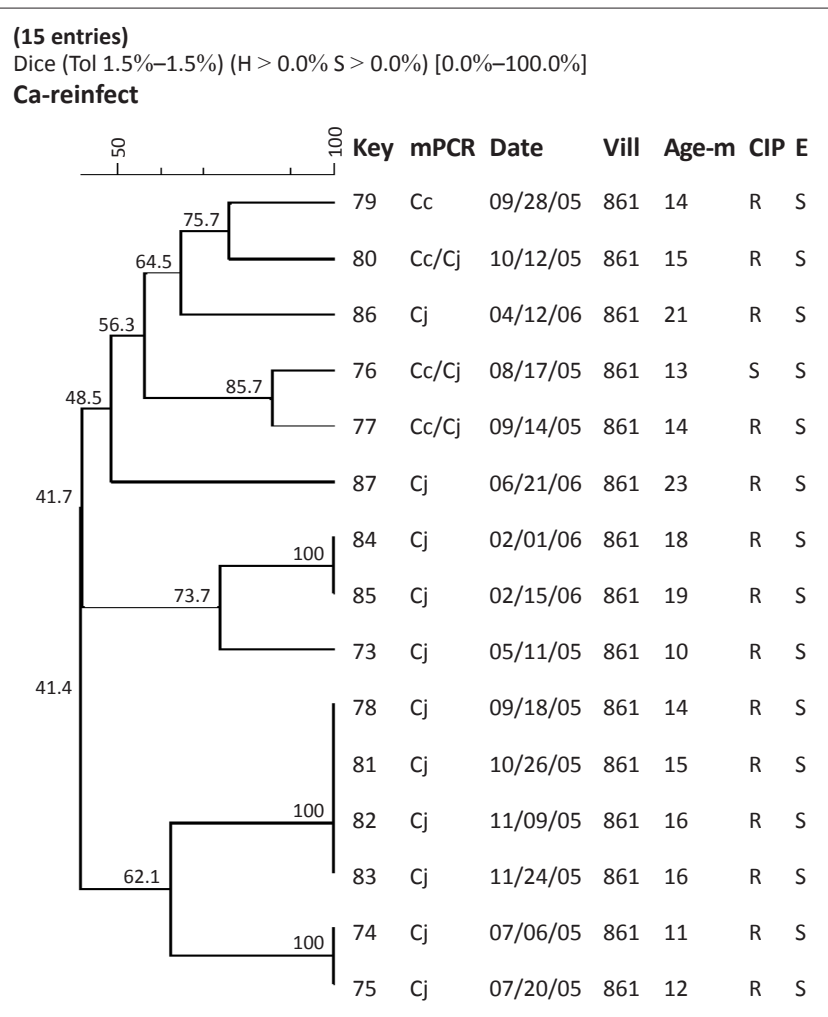

FIGURE 5: Smal macrorestriction profiling of Campylobacter spp. isolates from Child 13.

Abbreviations: Key: strain \#; mPCR: multiplex PCR, Date: date of isolation at the US Naval Medical Research Unit No. 3, laboratory; Pt\#: child \#, Vill: Village \#, Age-m: Age in months, Cc: C. coli, CJ: C. jejuni, R: resistant, S: susceptible, CIP: ciprofloxacin, E: erythromycin.

was obtained from parents or legal guardians of minors. No hazards were entailed in subject participation, but patients, physicians and the community could benefit from the results with regard to disease treatment, diagnosis and control.

Before sending samples to the laboratory, the privacy and confidentiality of the participating subjects were maintained by removing any direct personal identifiers and replacing them with codes (letters and numbers), not derived from or related to the personal information. The original identifiers were maintained securely and only traced back to the source at the physician's discretion for treatment or control purposes.

\section{Discussion}

Worldwide, thermotolerant Campylobacter species are amongst the most common causative agents of gastroenteritis. ${ }^{11,16}$ The main sources of infection include the consumption of unpasteurised milk, undercooked poultry or beef and contaminated water. ${ }^{17}$ In a two-year cohort study conducted in Egypt, many children showed serial isolations of Campylobacter spp., with at least one diarrhoeal episode (range $=1-4$ episodes per child), which may reflect the varying degrees of pathogenicity amongst Campylobacter isolates as well as the limited role of cross-protective mechanisms. This investigation attempted to explore whether these isolates represented the same or different infections. Previous studies have demonstrated age-related immunity, with a decrease in the case-to-infection ratio, absence of symptoms and shorter convalescent-phase excretion. ${ }^{18,19}$ This may or may not be supported by the observation that the enrolled children had a median age of eight months (range 3 months -14 months) at first isolation of Campylobacter, whilst the study had lasted for two years.

The species of all Campylobacter isolates were confirmed by the IpxA mPCR. We found that seven C. jejuni isolates detected by this method were negative using the hippurate hydrolysis test, which may be due to the variable expression levels of the N-benzoylglycine amidohydrolase (hippuricase) gene..$^{20}$ This finding supports the use of a genetic-based approach for the rapid and accurate identification of thermotolerant Campylobacter. . $^{8,21}$

C. jejuni isolates were the most commonly-recovered campylobacters ${ }^{22,23}$ and were most frequently associated with diarrhoeal episodes (79\%) amongst the 13 children. However, C. coli was responsible for diarrhoea in only three children, suggesting that although not as dominant as C. jejuni, the opportunity for environmental exposure to C. coli is significant in children in the Nile Delta. Globally, C. jejuni has been reported to cause more than $90 \%$ of Campylobacter infections,,$^{22,24}$ regardless of the severity of the clinical picture. ${ }^{18}$

To define the relationship amongst the Campylobacter isolates more accurately overall and from each individual child, isolates were pulsetyped using a protocol developed by PulseNet International that is specific for Campylobacter testing. ${ }^{7}$ The restriction enzyme, SmaI, was used since other options have been shown to provide less reproducible results. ${ }^{25}$ Analysing the profiles obtained per child, it appears that identical C. jejuni isolates $(96 \%-100 \%)$ were recovered frequently during diarrhoea episodes (as in Child 5,9 and 12) for intervals ranging between one and six weeks, whilst $C$. coli isolates were identical in only one child (Child 5), within two weeks. However, most C. coli isolates were distinguishable, with 50\% - 67\% PFGE band similarity, when recovered at periods from two weeks to seven months.

Assuming that an episode of diarrhoea may last for an average of one week, ${ }^{26}$ isolation of an identical strain after longer periods without diarrhoea may be regarded as being a convalescent-phase excretion..$^{27,28,29}$ For instance, in Child 13, indistinguishable $C$. jejuni isolates were recovered up to nine weeks after a diarrhoeal episode (Isolates 78 and 81-83). This is longer than reported earlier, ${ }^{3}$ which marked the presence of convalescent-phase excretion for only four weeks. However, at least one other study reported the shedding of Campylobacter isolates for more than nine months postinfection. ${ }^{27}$ In our study, Child 6 showed isolates with $>83 \%$ similarity that were identified seven months post-infection.

Reinfection with C. jejuni spp. was observed in Child 3, 4, 7 and 9, who developed diarrhoeal episodes in association with weakly-related isolates $(<33 \%, 42 \%, 31 \%$, and $36 \%$ band-matching, respectively) that appeared after variable 
periods of shedding, ranging from three days to 18 months. Child 11 was similar, but four consecutive diarrhoeal episodes occurred due to both $C$. jejuni and C. coli isolates (36\% similarity), with one to two week intervals between each. In Child 13, two identical C. jejuni CIP-resistant isolates were recovered from diarrhoeal episodes that took place nine weeks apart (September 2005 and 24 November), which may be regarded as recrudescence. This observation may be attributed to the lack of an adaptive immune response or resistance to antibiotic treatment. ${ }^{30,31}$ Prolonged Campylobacter diarrhoeal attacks have been reported to last for about 12 days only and were associated with CIP-resistant Campylobacter. ${ }^{32}$

Three children (Child 3, 7, 9) showed isolates identical to those causing diarrhoea, but at an earlier time before disease (10 days, three days and one week, respectively), which may be explained by the presence of a colonisation phase during the incubation period. ${ }^{33}$ It is also possible that preshedding of distinguishable Campylobacter strains is an in vivo predisposition through mutations at multiple sites (13 contingency loci) to augment bacterial virulence and speed up adaptation to the host. ${ }^{34,35}$ For instance, our PFGE results from Child 7 show that two indistinguishable $C$. jejuni isolates (Isolates 39 and 40) were distinct from an earlier isolate (Isolate 38 ), suggesting that Isolate 38 was rapidly replaced or dominated by the more invasive $C$. jejuni Isolate 39 , which resulted eventually in a second diarrhoeal episode.

Overall, this study identified 80 Campylobacter spp. isolates from 13 children showing six serial isolations during a twoyear study. The bacteria comprised 38 unique SmaI-PFGE profiles of C. jejuni and 24 profiles of $C$. coli at a similarity value of $>90 \%$ as described previously. ${ }^{36}$ This supports an immense genotypic diversity amongst Campylobacter species, an observation that has been attributed to the occurrence of inter- and intra-strain genetic exchanges during infection. ${ }^{28}$ Some children showed reinfection after variable periods from the first episode, whilst relapse was noted after seven weeks. Additional studies using multiple isolates from the same subject are required to advance our understanding of Campylobacter infection and immunity. Our data suggest that Campylobacter infection in children in endemic environments is a complex process; when children are exposed to multiple species and strains of Campylobacter, the same bacterium appears to be shed serially for between one to six weeks after the first exposure. Isolates that persisted for longer periods were relatively less similar as shown from the results of this study. Further detailed evaluation of the epidemiology and the isolates associated with diarrhoea and from non-diarrhoeal periods will be necessary in order to determine risk factors and mechanisms to prevent or control re-exposure of children in these settings.

\section{Acknowledgments}

We are highly appreciative of the expertise of Mr Abdel Hakam Abdel Fattah in the recovery and identification of Campylobacter spp. isolates. Also, we value the support of Dr Rania Abdel Khalek in analysing the PFGE results.

\section{Competing interest}

The authors declare that they have no financial or personal relationship(s) which may have inappropriately influenced them in writing this article.

\section{Authors' contributions}

A.M.G. (NAMRU-3) carried out microbiology and molecular studies and wrote the manuscript. M.O.W. (NAMRU-3) performed data analysis, results interpretation and helped in the writing of the manuscript. A.M.M. (NAMRU-3) coordinated the selection of study subjects and obtained the consent forms and samples. B.A.O. (NAMRU-3) performed critical revisions of the manuscript, made conceptual contributions and provided final approval for publication. M.M.Y. (Central Public Health Laboratories) participated in most of the laboratory experiments and J.D.K. (NAMRU-3) was the project leader.

\section{Copyright Assignment statement}

El-Gendy A, Wasfy M, Mansour A and Oyofo B are employees of the U.S. Government. This work was prepared as part of our official duties. Title 17 U.S.C. $\$ 105$ provides that 'Copyright protection under this title is not available for any work of the United States Government.' Title 17 U.S.C. \$101 defines a U.S. Government work as a work prepared by a military service member or employee of the U.S. Government as part of that person's official duties.

\section{References}

1. Blaser MJ. Epidemiologic and clinical features of Campylobacter jejuni infections J Infect Dis. 1997;176 Suppl 2:S103-105. http://dx.doi.org/10.1086/513780, PMid:9396691

2. Wasfy MO, Oyofo BA, David JC, et al. Isolation and antibiotic susceptibility of Salmonella, Shigella, and Campylobacter from acute enteric infections in Egypt. Health Popul Nutr. 2000;18(1):33-38. PMid:11014768

3. Rao MR, Naficy AB, Savarino SJ, et al. Pathogenicity and convalescent excretion of Campylobacter in rural Egyptian children. Am J Epidemiol. 2001;154(2):166-173. http://dx.doi.org/10.1093/aje/154.2.166, PMid:11447051

4. Putnam SD, Frenck RW, Riddle MS, et al. Antimicrobial susceptibility trends in Campylobacter jejuni and Campylobacter coli isolated from a rural Egyptian pediatric population with diarrhea. Diagn Microbiol Infect Dis. 2003;47(4):601-608. http:// population with diarrhea. Diagn Microbiol In
dx.doi.org/10.1016/S0732-8893(03)00154-8

5. Praakle-Amin $\mathrm{K}$, Roasto $\mathrm{M}$, Korkeala $\mathrm{H}$, et al. PFGE genotyping and antimicrobial susceptibility of Campylobacter in retail poultry meat in Estonia. Int J Food Microbiol. 2007;114(1):105-112. http://dx.doi.org/10.1016/j.ijfoodmicro.2006.10.034, PMid:17182145

6. Ono K, Kurazono T, Niwa $\mathrm{H}$, et al. Comparison of three methods for epidemiological typing of Campylobacter jejuni and C. coli. Curr Microbiol. 2003;47 (5):364-371. http://dx.doi.org/10.1007/s00284-002-4037-6, PMid:14669910

7. Ribot EM, Fitzgerald C, Kubota K, et al. Rapid pulsed-field gel electrophoresis protocol for subtyping of Campylobacter jejuni. J Clin Microbiol. 2001;39(5): 1889-1894. http://dx.doi.org/10.1128/JCM.39.5.1889-1894.2001, PMid:11326009, PMCid:88044

8. Nakari UM, Puhakka A, Siitonen A. Correct identification and discrimination between Campylobacter jejuni and C. coli by a standardized hippurate test and speciesspecific polymerase chain reaction. Eur J Clin Microbiol Infect Dis. 2008;27(7): 513-518. http://dx.doi.org/10.1007/s10096-008-0467-9, PMid:18317822

9. Saenz $Y$, Zarazaga $M$, Lantero $M$, et al. Antibiotic resistance in Campylobacter strains isolated from animals, foods, and humans in Spain in 1997-1998. Antimicrob Agents Chemother. 2000;44(2):267-271. http://dx.doi.org/10.1128/AAC.44.2.267271.2000, PMid:10639348, PMCid:89669

10. Morris GK, el Sherbeeny MR, Patton CM, et al. Comparison of four hippurate hydrolysis methods for identification of thermophilic Campylobacter spp. J Clin Microbiol. 1985;22(5):714-718. PMid:3902875, PMCid:268512

11. Klena JD, Parker CT, Knibb K, et al. Differentiation of Campylobacter coli, Campylobacter jejuni, Campylobacter lari, and Campylobacter upsaliensis by a multiplex PCR developed from the nucleotide sequence of the lipid A gene IpxA. J Clin Microbiol. 2004;42(12):5549-5557. http://dx.doi.org/10.1128/JCM.42.12.55495557.2004, PMid:15583280, PMCid:535264 
12. Ge B, Bodeis S, Walker RD, et al. Comparison of the Etest and agar dilution for in vitro antimicrobial susceptibility testing of Campylobacter. J Antimicrob Chemother 2002;50(4):487-494. http://dx.doi.org/10.1093/jac/dkf162, PMid:12356792

13. Luangtongkum T, Morishita TY, El-Tayeb AB, et al. Comparison of antimicrobial susceptibility testing of Campylobacter spp. by the agar dilution and the aga disk diffusion methods. J Clin Microbiol. 2007:45(2):590-594. http://dx.doi.org/ 10.1128/JCM.00986-06, PMid:17122005, PMCid:1829028

14. Gaudreau C, Girouard Y, Ringuette L, et al. Comparison of disk diffusion and agar dilution methods for erythromycin and ciprofloxacin susceptibility testin of Campylobacter jejuni subsp. jejuni. Antimicrob Agents Chemother. 2007, 51(4):1524-1526. http://dx.doi.org/10.1128/AAC.00905-06, PMid:17261628, PMCid:1855498

15. Lutgen EM, McEvoy JM, Sherwood JS, et al. Antimicrobial resistance profiling and molecular subtyping of Campylobacter spp. from processed turkey. BMC Microbiol. 2009;9:203. http://dx.doi.org/10.1186/1471-2180-9-203, PMid:19772592, PMCid:2758883

16. Allos BM. Campylobacter jejuni infections: update on emerging issues and trends. Clin Infect Dis. 2001;32(8):1201-1206. http://dx.doi.org/10.1086/319760 PMid:11283810

17. Denis M, Chidaine B, Laisney MJ, et al. Comparison of genetic profiles of Campylobacter strains isolated from poultry, pig and Campylobacter human infections in Brittany, France. Pathol Biol (Paris). 2009
org/10.1016/j.patbio.2008.04.007, PMid:18534783

18. Carvalho AC, Ruiz-Palacios GM, Ramos-Cervantes $P$, et al. Molecular characterization of invasive and noninvasive Campylobacter jejuni and Campylobacter coli isolates. J
Clin Microbiol. 2001;39(4):1353-1359. http://dx.doi.org/10.1128/JCM.39.4.1353Clin Microbiol. 2001;39(4):1353-1359. http://d

19. van Vliet AH, Ketley JM. Pathogenesis of enteric Campylobacter infection. Symp Ser Soc Appl Microbiol. 2001;30:45S-56S. http://dx.doi.org/10.1046/j.13652672.2001.01353.x, PMid:11422560

20. Hani EK, Chan VL. Expression and characterization of Campylobacter jejun benzoylglycine amidohydrolase (hippuricase) gene in Escherichia coli. J Bacteriol. 1995;177(9):2396-2402. PMid:7730270, PMCid:176897

21. Willoughby K, Nettleton PF, Quirie M, et al. A multiplex polymerase chain reaction to detect and differentiate Campylobacter fetus subspecies fetus and Campylobacte fetus -species venerealis: use on UK isolates of C. fetus and other Campylobacte spp. J Appl Microbiol. 2005;99(4):758-766. http://dx.doi.org/10.1111/j.1365 2672.2005.02680.x, PMid:16162226

22. Wardak S, Duda U, Krasowska D, et al. [Campylobacter spp. as a leading cause of human bacterial gastroenteritis in selected region of Poland]. Przegl Epidemiol. 2009;63(4):531-537. PMid:20120952

23. Wardak S, Szych J. [Prevalence of pathogenic genes of Campylobacter jejun isolated from humans in Poland between 2003-2005]. Med Dosw Mikrobiol. 2006;58(3):217-222. PMid:17340996

24. Wardak S, Szych J, Sadkowska-Todys M. The first report on Campylobacter coli family outbreak detected in Poland in 2006. Euro Surveill. 2008;13(9):pii:8052. PMid:18445405
25. Clark CG, Price L, Ahmed R, et al. Characterization of waterborne outbreakassociated Campylobacter jejuni, Walkerton, Ontario. Emerg Infect Dis. 2003; 9(10):1232-1241. http://dx.doi.org/10.3201/eid0910.020584, PMid:14609457, 9(10): $1232-1241$

26. Cawthraw SA, Feldman RA, Sayers AR, et al. Long-term antibody responses following human infection with Campylobacter jejuni. Clin Exp Immunol. 2002;130(1): 101-106. http://dx.doi.org/10.1046/j.1365-2249.2002.01966.x, PMid:12296859, PMCid:1906500

27. Albert MJ, Leach $A$, Asche $V$, et al. Serotype distribution of Campylobacter jejuni and Campylobacter coli isolated from hospitalized patients with diarrhea in centra Australia. J Clin Microbiol. 1992;30(1):207-210. PMid:1370848, PMCid:265021

28. de Boer P, Wagenaar JA, Achterberg RP, et al. Generation of Campylobacter jejuni genetic diversity in vivo. Mol Microbiol. 2002;44(2):351-359. http://dx.doi. org/10.1046/j.1365-2958.2002.02930.x, PMid:11972775

29. Yabe S, Higuchi W, Iwao Y, et al. Molecular typing of Campylobacter jejuni and C. coli from chickens and patients with gastritis or Guillain-Barré syndrome based on multilocus sequence types and pulsed-field gel electrophoresis patterns. Microbiol Immunol. 2010;54(6):362-367. http://dx.doi.org/10.1111/j.13480421.2010.00222.x, PMid:20536735

30. Tribble DR, Sanders JW, Pang LW, et al. Traveler's diarrhea in Thailand: randomized, double-blind trial comparing single-dose and 3-day azithromycin-based regimens with a 3-day levofloxacin regimen. Clin Infect Dis. 2007;44(3):338-346. http:// dx.doi.org/10.1086/510589, PMid:17205438

31. Tribble DR, Baqar S, Carmolli MP, et al. Campylobacter jejuni strain CG8421: a refined model for the study of Campylobacteriosis and evaluation of Campylobacter vaccines in human subjects. Clin Infect Dis. 2009;49(10):1512-1519. http://dx.doi org/10.1086/644622, PMid:19842970

32. Nelson JM, Smith KE, Vugia DJ, et al. Prolonged diarrhea due to ciprofloxacinresistant campylobacter infection. J Infect Dis. 2004;190(6):1150-1157. http:// dx.doi.org/10.1086/423282, PMid:15319866

33. Jones FR, Baqar S, Gozalo A, et al. New World monkey Aotus nancymae as a mode for Campylobacter jejuni infection and immunity. Infect Immun. 2006;74(1):790793. PMid:16369042, PMCid:1346678

34. Luo N, Sahin O, Lin J, et al. In vivo selection of Campylobacter isolates with high levels of fluoroquinolone resistance associated with gyrA mutations and the function of the CmeABC efflux pump. Antimicrob Agents Chemother. 2003;47(1): 390-394. http://dx.doi.org/10.1128/AAC.47.1.390-394.2003, PMid:12499221 PMCid:148968

35. Jerome JP, Bell JA, Plovanich-Jones $\mathrm{AE}$, et al. Standing genetic variation in contingency loci drives the rapid adaptation of Campylobacter jejuni to a novel host. PLOS ONE. 2011;6(1):e16399. http://dx.doi.org/10.1371/journal.pone.0016399, PMid:21283682, PMCid:3025981

36. Nadeau E, Messier S, Quessy S. Comparison of Campylobacter isolates from poultry and humans: association between in vitro virulence properties, biotypes, and pulsed-field gel electrophoresis clusters. Appl Environ Microbiol. 2003;69(10): 63166320. http://dx.doi.org/10.1128/AEM.69.10.6316-6320.2003, PMid:14532099, PMCid:201179 